\title{
A ARQUITETURA DA INFORMAÇÃO E A SINTAXE DAS LINGUAGENS IMAGÉTICAS NO WEBSITE GUIA GAY FLORIPA ${ }^{1}$
}

\author{
The Information Architecture and the imagetic languages in the Gay Floripa Guide \\ website
}

\author{
Jean Fernandes Brito', Rafaela Carolina da Silva ${ }^{2}$, Márcio Matias ${ }^{3}$ \\ (1) Universidade Federal de Santa Catarina, Florianópolis, jjeanfernandes@gmail.com \\ (2) Universidade Estadual Paulista Júlio de Mesquita Filho, Marília/SP, \\ rafaelacarolinasilva@gmail.com. \\ (3) Universidade Federal de Santa Catarina, Florianópolis, matias97@gmail.com
}

\begin{abstract}
Resumo:
O mundo após o fim da II Guerra Mundial abarca a inserção de meios automáticos na produção e no oferecimento de serviços, deixando de lado a linearidade, e permitindo a mistura de diferentes modalidades de linguagens. Logo, a proposta da pesquisa é analisar a Arquitetura da Informação e os elementos da linguagem imagética no website Guia Gay Floripa. A natureza da pesquisa é qualitativa, descritiva e exploratória. Para a análise do objeto de estudo e o alcance dos resultados esperados, foram analisados os elementos da Arquitetura da Informação presentes na plataforma. Notou-se que o website apresenta um sistema de rotulagem e de navegação capaz de estruturar as mensagens a serem disseminadas, com o uso adequado da convergência de linguagens e da Arquitetura da Informação em frases informativas e imagens que despertam a curiosidade do uso e a facilidade no acesso à informação. Conclui-se que a utilização de ambientes informacionais digitais para a disponibilização de informações turísticas para o público LGBT torna-se relevante, tendo em vista seu caráter informativo e a maior aproximação da instituição com seus usuários a partir desse ambiente colaborativo.
\end{abstract}

Palavras-chave: Arquitetura da Informação; Linguagens imagéticas; Website Guia Gay Floripa; Disponibilização da informação; Uso inteligente da informação.

\begin{abstract}
:
The world after the end of II World War includes the insertion of automatic means in the production and in the offering of services, leaving aside the linearity, and allowing the miscellany of different modalities of language. Therefore, the research proposal is to analyze the Information Architecture and the elements of the imagetic language in the Gay Floripa Guide website. The nature of the research is qualitative, descriptive and exploratory. For the analysis of the object of study and to reach of the expected results, this research analyzed the elements of Information Architecture present in the platform. It was noted that the creators of the site know how to structure the messages to be disseminated, with the appropriate use of convergence of languages and Information Architecture in informative phrases and images that arouse the curiosity of the use and the ease in access to information. It was concluded that the use of digital information environments for the provision of tourist information becomes relevant in view of its informative nature, and the greater approximation of the institution with its users from this collaborative environment.
\end{abstract}

\footnotetext{
${ }^{1}$ Esse artigo é parte integrante da dissertação de mestrado do primeiro autor, do Programa de Pós Graduação em Ciência da Informação - PGCIN da Universidade Federal de Santa Catarina - UFSC e possui como temas gerais a Arquitetura da Informação e Experiência do Usuário em websites de turismo LGBT
} 
Keywords: Information Architecture; Imagetic languages; Website Guia Gay Floripa; Provision of information; Intelligent use of information.

\section{Introdução}

O mundo após o fim da II Guerra Mundial abarca a inserção de meios automáticos na produção e no oferecimento de serviços, deixando de lado a linearidade, e permitindo a mistura de diferentes modalidades de "[...] linguagem e pensamento textos, imagens, sons, ruídos e vozes em ambientes multimidiáticos - a digitalização também permite a organização reticular dos fluxos informacionais" (SANTAELLA, 2001, p. 393) no tratamento, armazenamento e disseminação da informação.

Baseando-se na informação acima, esta pesquisa tomou como base a comunidade das Lésbicas, Gays, Bissexuais e Transgêneros (LGBT), uma população ativa e que se utiliza das tecnologias digitais como forma de ampliação e manifestação da informação, não se caracterizando como minorias sociais, mas como um movimento aberto.

O movimento Gays, Lésbicas e Simpatizantes (GLS), como antigamente era designado, transformou-se, nos últimos anos, em um dos movimentos sociais mais expressivos do país (VIANA, 2006). Segundo a autora, alguns traços dessa expressão são desenhados pela presença de suas "rotinas" de ações, de seus interesses, de seus aliados e da sua representação em diversos espaços da sociedade, levando em conta o uso das tecnologias em seus diversos contextos: Turismo, Relacionamentos e Fóruns de discussão.
Nesse sentido, o objeto de estudo deste artigo é o website Guia Gay Floripa ${ }^{2}$ (Apêndice A), um ambiente informacional digital que disponibiliza informações turísticas para o público gay na cidade de Florianópolis/Brasil. A mesma rede desse ambiente se concentra em outros websites, se expandido às cidades de São Paulo/Brasil, Salvador/Brasil, Belo Horizonte/Brasil e Brasília/Brasil.

A comunidade LGBT se apropria das informações do website na medida em que se cria um espaço de visibilidade, divulgação e ampliação do turismo com o uso das Tecnologias de informação e Comunicação (TIC). Logo, pensar em ambientes digitais para o público LGBT é ampliar a participação dessa comunidade em sociedade, otimizando o acesso à informação.

Oliveira e Vidotti (2016) apresentam a ideia de Arquitetura da Informação como uma forma de enxergar e analisar os sites da web e as intranets como sendo 'um todo'. Trata-se de um ambiente de informação digital que justapõe, articula e integra as partes de organização, de rotulagem, de busca, de navegação e de representação da informação, produzindo um ambiente em que o usuário pode acessar, usar e se apropriar de informações de natureza digital.

Sob essa perspectiva, Bembem, Oliveira e Santos (2015) destacam que a Ciência da Informação $(\mathrm{Cl})$ vive o tempo do conhecimento interativo, que visa significativas mudanças nas formas de elaborar e de acessar o conhecimento, utilizando tecnologias digitais como

\footnotetext{
${ }^{2}$ Disponível em:

http://www.guiagayfloripa.com.br/2/home.htm
}

Acesso em 28.ago.2017 
suporte. As informações na ambiente web são compartilhadas em tempo real e, em termos de espaço, possibilitam a troca e a dinamização de informações, independentemente da distância existente entre os usuários, que ocorre, basicamente, em uma mesma velocidade.

Nesse contexto, os ambientes informacionais digitais, como as bibliotecas digitais, os repositórios digitais, os portais de notícias, dentre outros, influenciam no processo de transmissão da informação e na adequação desses ambientes ao usuário quanto à usabilidade, Arquitetura da Informação, design, experiência do usuário etc.

Assim, percebe-se, com o decorrer da história, que o desejo de criar é uma constante à espécie humana, permeando, na atualidade, a passagem dos meios analógicos às TIC, que englobam os meios digitais.

$\mathrm{Na}$ utilização de ambientes digitais colaborativos, o modo de construção do conhecimento se dá, por um lado, por meio da interação entre o homem e a máquina, o que permite uma maior facilidade na articulação das linguagens convergentes do ambiente através da hipertextualidade e da multimodalidade na escolha do conteúdo a ser pesquisado. A interação homem-máquina ocorre quando um ou mais homens, articulando seus conhecimentos na criação de conteúdos digitais, trabalham as plataformas digitais desde sua criação até o compartilhamento de informações em rede.

Por outro lado, nos ambientes digitais também existe a inteligência artificial, que permite a construção de conhecimentos de forma similar à humana, contudo, exibida por mecanismos ou softwares. Essas duas formas de compartilhamento de informação se complementam na construção de conhecimentos em ambientes digitais.

Partindo da ideia de Dondis (2003), no que se diz respeito ao potencial da imagem no processo de absorção das informações, esta pesquisa tem como pressuposto o trabalho do bibliotecário, acrescentando aos seus conhecimentos o uso de elementos imagéticos, o que pode contribuir para a alfabetização digital. Dessa maneira, acredita-se que os elementos imagéticos devam se relacionar com 0 tipo de público e com a maneira como o conteúdo é visualizado.

Assim, este estudo busca compreender como a utilização das linguagens imagéticas e da Arquitetura da Informação podem contribuir para o acesso fácil e intuitivo às informações contidas em ambientes digitais. Após as considerações apresentadas, chegou-se à seguinte indagação: "Como o website Guia Gay Floripa está estruturado em termos de Arquitetura da Informação e de linguagens imagéticas?".

Sendo assim, essa pesquisa está sustentada pelo eixo temático "Aplicações em tecnologias da informação", pertecente ao I Workshop de Informação, Dados e Tecnologia (WIDaT), na medida em que estabelece uma tessitura teórica entre Arquitetura da Informação e linguagens imagéticas para, otimização 0 acesso à informações turísticas ao público gay.

É necessário, portanto, que os ambientes informacionais digitais estejam adequados às necessidades, às competências e aos comportamentos informacionais dos usuários, para que esses venham a construir conhecimento a partir das informações encontradas na Internet.

Segundo Arango, Morville e Rosenfeld (2015), a Arquitetura da Informação é constituída por: sistema de organização, sistema de navegação, sistema de rotulagem, sistema de busca e sistemas de representação, observados por meio 
de metadados, vocabulários controlados e tesauros.

A Arquitetura da Informação reúne uma gama de aspectos da Ciência da Informação, da Biblioteconomia e da Ciência da Computação, que têm sido frequentemente divulgados nos assuntos: estudo de usuários, cognição de usuários, políticas de informação, projeto de ferramenta de busca, projeto de interface, metadados e classificação (CAMARGO; VIDOTTI, 2011, p. 25).

A linguagem imagética pode ser conceituada como uma reunião de informações transmitidas e compreendidas direta e imediatamente. Ao contrário da linguagem verbal, a linguagem imagética pressupõe não somente a inteligência humana, mas também uma inspiração não cerebral, decorrente do sistema da visão, do olhar humano. (DONDIS, 2003).

Dessa maneira, a interdisciplinaridade entre a Arquitetura da Informação e as linguagens imagéticas, no âmbito da Ciência da Informação, mais especificamente na análise de websites, está no fato de as linguagens imagéticas proporcionarem subsídios para a estruturação dessas plataformas no que diz respeito ao sistema de rotulagem. Nessa perspectiva, as linguagens imagéticas trabalham a estrutura de rotulagem do website, tornando-o atrativo aos olhos de quem utilizará a plataforma.

\section{Objetivos}

O objetivo geral desta pesquisa é analisar a Arquitetura da Informação e os elementos da linguagem imagética no website Guia Gay Floripa, de modo a otimizar 0 acesso a informações turísticas pela comunidade LGBT. De modo mais específico, caracterizar os instrumentos que permitem a navegação do usuário de modo mais intuitivo nessa plataforma.

\section{Procedimentos Metodológicos}

A natureza da pesquisa é qualitativa, do tipo descritiva, exploratória e analítica, cujo sujeito é o website Guia Gay Floripa. Para a análise do objeto de pesquisa e o alcance dos resultados esperados, foram pesquisados os elementos da Arquitetura da Informação estudados por Arango, Morville e Rosenfeld (2015), assim como estudos da sintaxe da linguagem imagética.

A tipologia exploratória consiste em aprofundar e sintetizar aspectos técnicos e conceituais, obtidos por meio de um referencial bibliográfico $e$ vinculados ao objeto de estudo. A tipologia descritiva procura conhecer e entender as diversas relações que ocorrem no contexto social, político, econômico e nos demais aspectos que envolvem a sociedade.

Para tanto, observou-se a integração do website Guia Gay Floripa no contexto da sociedade na qual ele está inserido, a fim de refletir e de trazer resultados para sustentar a problemática do estudo. 0 método de Estudo de Caso auxiliou no desenvolvimento da pesquisa no sentido de levantar as características da plataforma que permitem a otimização do seu uso pelos usuários.

\section{Resultados}

A convergência de linguagens, advinda das possibilidades de atuação em diferentes suportes de trabalho, permitiu o contato com as linguagens virtuais, ou seja, com os conceitos que simulam, por meio da computação, os produtos e serviços do mundo real. Dessa maneira, o uso de tecnologias digitais é intensificado. O elemento mais importante de uma imagem é a tonalidade de sua cor, que varia conforme a presença de luz incidente sobre a composição (DONDIS, 2003). Dessa forma, quanto maior for a quantidade luz presente em uma cor, mais clara ela é, e quanto menor for essa quantidade de luz, mais escura ela é; a ausência 
total de luz determina a cor preta; portanto, é a natureza tonal quem determina o que os olhos humanos vêem.

O que a luz revela, juntamente com a percepção do homem, identifica os demais elementos visuais. São eles:

- Ponto: menor unidade da comunicação imagética, que varia sua quantidade de acordo com a complexidade da imagem;

- Linha: proximidade entre vários pontos, chegando ao momento onde não é possível identificá-los individualmente - é a linha quem dá os primeiros passos à ideia de movimento da imagem;

- Cor: as cores mais básicas, denominadas de primárias, são o azul, o vermelho e o verde que, quando combinadas, compõem as cores secundárias e terciárias; as cores frias são aquelas que instigam a serenidade, a refrescância e a paz, diferentemente das quentes, que remetem ao agito e ao calor;

- A junção de cores pode ser cromática (diferentes tonalidades de cores afins), acromática (onde não é possível distinguir as cores) e saturadas (cores relativamente puras, próximas da matiz do cinza);

- Forma: a linha envolve uma forma e é a partir de três formas básicas - círculo, quadrado e triângulo - que são formadas as demais formas;

- Direção: é o lado para onde a linha, a forma, a cor ou a imagem em si se dirige. Existem três direções básicas na linguagem imagética: a horizontal e a vertical - para o quadrado; a diagonal - para o triângulo; e a curva - para o círculo; - Textura: é o elemento que dá à visão a sensação do tato;

- Escala: a capacidade que os elementos visuais possuem de definirem-se uns aos outros, relação entre o grande e o pequeno;
- Dimensão: uso de pontos de fuga e estratégias para que as imagens demonstrem ter mais de uma dimensão, como é o caso das imagens em três dimensões (3D) usadas para, mesmo que implicitamente, instigar uma maior relação com os objetos originais;

- Movimento: técnica que ilude os olhos humanos, dando a sensação de que a imagem está se mexendo (SILVA, 2014).

Nessa perspectiva, as técnicas de tratamento das imagens no website Guia Gay Floripa variam de acordo com os níveis de equilíbrio e de nivelamento aos olhos humanos. $O$ intuito é impactar, portanto, trabalha-se a tensão, o contraste de cores, as texturas, a profundidade e a distribuição de conteúdos na plataforma.

O website é estruturado de forma a tornar a informação disponibilizada cativante, direcionada pelo uso da arte, mas mantendo a complexidade dos assuntos e, ao mesmo tempo, proporcionando diferentes meios de acesso à informação àqueles que não teriam oportunidade de se relacionar com esses conteúdos, se não por meio da plataforma.

No que diz respeito à análise da Arquitetura da Informação, verificou-se a existência dos seguintes elementos: esquemas exatos alfabéticos, cronológicos e geográficos; esquemas ambíguos, distribuídos por tópicos e direcionados a públicos específicos, pertencentes ao sistema de organização; elementos de navegação global e contextual; navegação por links contextuais, cabeçalhos, rótulos e termos de indexação; assim como preferência pela procura de itens conhecidos, dentro do sistema de busca.

Sendo assim, percebeu-se que a intenção do website é resgatar informações do dia a dia do mundo LGBT, de modo a informar à sociedade, 
em seus diferentes gêneros e idades, a importância dessa comunidade no desenvolvimento político, econômico e social, bem como a necessidade de inclusão desse público nas dinâmicas sociais. Além disso, observou-se o crescimento do acesso ao website por públicos diferenciados, o que corrobora para a inserção da comunidade LGBT nas atividades do Estado, mostrando as dimensões abrangentes que esse público atingiu nos últimos anos.

\section{Considerações Finais}

A utilização de ambientes informacionais digitais para a disponibilização de informações turísticas torna-se relevante tendo em vista seu caráter informativo e a maior aproximação da instituição com seus usuários, a partir desse ambiente. $O$ website é um ambiente colaborativo, logo, notou-se a importância dada aos elementos da Arquitetura da Informação, assim como a preocupação com o design de interação, com a experiência do usuário, com a usabilidade, com a acessibilidade, entre outras áreas ligadas à Ciência da Informação.

Nessa perspectiva, o usuário consegue entender 0 significado geral da informação disponibilizada pelo website. Ao interpretar tal informação, o usuário especifica o conteúdo da mensagem recebida, passando a criar novas informações e a transmiti-las novamente - princípio da comunicação humana.

Por conseguinte, o que faz com que uma imagem se torne atrativa ou não aos olhos de quem as vê é o jeito, a maneira como a mesma está sendo vista e demonstrada, sendo disponibilizada por meio de suportes de informação analógicos ou digitais.

\section{Referências}

ARANGO, J.; ROSENFELD, L.; MORVILLE, P. Information

architecture: for the web and beyond. Canadá: O’Reilly Media, 2015.

BEMBEM, A. H. C.; OLIVEIRA, H. P. C. de; SANTOS, P. L. V. A. da C. O paradigma social e o tempo do conhecimento interativo: perspectivas e desafios para uma Arquitetura da Informação Pervasiva. Perspectivas em Ciência da Informação, v. 20, n. 4, p. 181-196, out./dez. Disponível em: $<$ http://www.scielo.br/pdf/pci/v20n4/141 3-9936-pci-20-04-00181.pdf>. Acesso em: 28 ago. 2017

\section{CAMARGO, L. S. A. Arquitetura da Informação para biblioteca digital personalizável. 2004. Dissertação. (Mestrado em Ciência da Informação) - Universidade Estadual Paulista. 2004. Disponível em: <https://www.marilia.unesp.br/Home/ Pos-Graduacao/Cienciadalnformaca o/Dissertacoes/camargo Isa me ma r.pdf>. Acesso em: 28 ago.2017.}

DONDIS, D. A. Sintaxe da linguagem visual. Tradução de Jefferson Luiz Camargo. 2. ed. São Paulo: Martins Fontes, 2003.

GUIA GAY FLORIPA. Disponível em: $<$ http://www.guiagayfloripa.com.br/2/ho me.htm>. Acesso em: 18 jul. 2017.

OLIVEIRA, H. P. C. de. Arquitetura da Informação pervasiva: contribuições conceituais. 2014. 202 f. Tese (Doutorado em Ciência da Informação) - Faculdade de Filosofia e Ciências, Universidade Estadual Paulista, Marília, 2014.Disponível em: $<$ http://www.marilia.unesp.br/Home/Pos -Graduacao/Cienciadalnformacao/Diss ertacoes/oliveira hpc do mar.pdf>.

Acesso em 28 ago. 2017.

SANTAELLA, L. Matrizes da 
linguagem visual e pensamento:

sonora visual verbal. 3. ed. São Paulo:

lluminuras, 2001.

SILVA, R. C. da. O uso da informação imagética no processo da inclusão digital: uma perspectiva para atuações bibliotecárias. 2014. Trabalho de Conclusão de Curso. (Graduação em Biblioteconomia). Universidade Estadual Paulista. 2014.

VIANA, Marislene Rocha. Lutas sociais e redes de movimentos no final do século XX. In: Revista Serviço Social e Sociedade. N64. São Paulo: Cortez, 2000.

VIDOTTI, S. A. B. G; CUSIN, C. A.; CORRADI, J. A. M. Acessibilidade digital sob o prisma da Arquitetura da Informação. In: GUIMARÃES, J. A. C.; FUJITA, M. S. L. Ensino e pesquisa em biblioteconomia no Brasil: a emergência de um novo olhar. São Paulo: Cultura Acadêmica, 2008.

VECHIATO, F. L.; DOMINGUES, V. J.; REBELO, A. M. S.; FERNAL, A. Aplicação da Arquitetura da Informação, da usabilidade e da acessibilidade em websites de arquivos. In: CONGRESSO NACIONAL DE ARQUIVOLOGIA (CNA), 5., 2012, Salvador. Anais...

Salvador, 2012. Disponível em:

$<$ http://www.enara.org.br/cna2012/anai s/AnaisVCNA2012.pdf>. Acesso em:

10 mar. 2017. 
Apêndice A - Home website Guia Gay Floripa

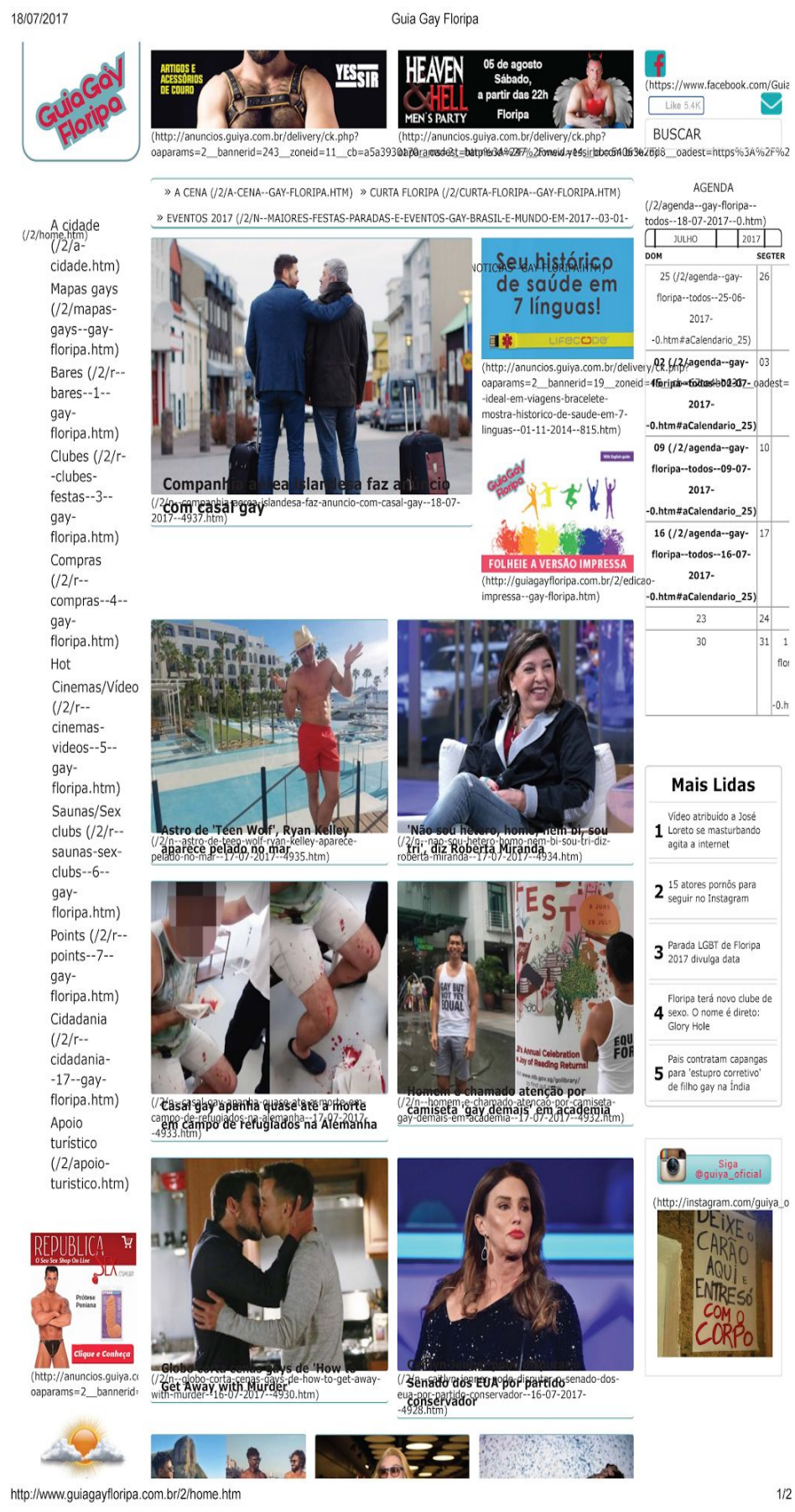

